not recognised or treated psychologically. One can only speculate as to future alcohol and benzodiazepine problems.

Later I spoke with old women 'displaced' from Vosoko who were accommodated in a hotel on the coast. They helped me to realise what the 'land' meant to them. They seemed almost part of it, only to be cruelly wrenched from it and planted in the parched coastline of the Adriatic where so little grows. Here too everyone was 'addicted' to sleeping tablets.

I had been more affected by my visits than I cared to admit, especially the last one. It took me at least two weeks to get round to writing my report. I didn't want to discuss the visit with anyone and felt an outsider at my place of work. I had many disturbing dreams which continue intermittently and revolve around helplessness and being shot at. And I didn't even see anything that could have been described as out of the normal range of human experiencel In fact the whole experience is best summed up as surreal.

\section{Conclusion}

1993 was a year to remember. The experience was extremely valuable for me (and hopefully those with whom I worked). I suspect that this may well be the future of Army psychiatry which will prove stimulating on many levels. There will be the physical, intellectual and emotional challenges posed by such deployments and the chance to help soldiers, local ctvilian faclitities, the UN and other aid agencies to deal with the threats to their mental health posed by such conflicts.

Major I.P. Palmer, Senior Spectalist in Military Psychiatry, Queen Elizabeth Military Hospital, Woolwich SE18 4QH

\title{
GMC's guidance on confidentiality
}

The General Medical Councll have agreed that part of a letter which they wrote to a member of the College containing their current policy on confidentiality can be published in the Psychiatric Bulletin. This letter was written in response to a specific enquiry.

The Council's guidance on confidentlality distinguishes between disclosures made within health care teams, which relate primarlly to the care and treatment of patients, and those made for other purposes, for example to assist the police or the courts etc. In the former case, doctors should ensure that arrangements are made for patients to be informed, in general terms, about disclosures within health care teams, but they may share any information which members of the team need to know in order to perform their duties. This may, of course, include details of the patient's history.

When disclosures are made for other purposes, the explicit consent of the patient should be sought except in the rare circumstances set out in the Council's guidance. One such circumstance is, where failure to disclose information would place the patient or someone else at risk of death or serious harm. As in other cases, doctors must be able to justify decisions taken on this ground. Disclosure of a patient's medical history may in some cases be necessary and relevant, but doctors must be able to demonstrate that, for example, information they have held for some time gives rise to a risk which had not been apparent earlier.

The Council fully recognises that doctors are often required to make difficult decisions about whether to disclose confidential information about patients without consent. Doctors should give careful consideration to the circumstances of every case in which such decisions must be made and would often be whe to consult their medical defence society or senior colleagues about whether to disclose information, and if so, what form the disclosure should take.

Jane O'Brien, General Medical Councl, 44 Hallam Street, London WIN GAE 